\title{
Organizing Serial Records at the Ohio State University Libraries
}

Mr. Skipper is assistant acquisition librarian, Ohio State University Libraries.

$\mathrm{T}$ HE HISTORY of administrative records development at the Ohio State University Libraries is, perhaps, typical of many institutions. Growth was slow, the necessity for administrative efficiency of records was not compelling, and as a consequence, the design and maintenance of serial records was a matter of small importance. Two factors conspired to turn this relatively pleasant situation into a problem of unmanageable proportions. 'The first was the law of exponential growth of libraries which has been effectively suggested by Fremont Rider. ${ }^{1}$ A collection growing by geometric rather than arithmetic proportions does not allow time for unorganized, evolutionary adjustment in records keeping. 'The second factor was the lean years of the depression which, of necessity, caused the library to break its serial records down into units small enough to be mastered by clerical personnel and student assistants. Attempts to integrate and centralize serial records were postponed by equipment and personnel shortage incident to World War II.

At the time that Ohio State found it possible to remedy the situation, the library maintained the following serial records:

I. Public dictionary catalog (recorded editors, titles, cross references. Referred to the public periodical catalog for holdings)

2. Public periodical catalog (recorded

1 Rider, Fremont. The Scholar and the Future of the Research Library. New York, Hadham Press, I944. titles, cross references and holdings of cataloged serials)

3. Shelf list (recorded bound and unbound classified holdings)

4. Sheet shelf list (recorded accession numbers and supplementary notes which are too voluminous to go on the shelf list card)

5. Accession book (recorded each bound serial with its accession number)

6. Order card (recorded complete bibliographic record, date of order and receipt, price, and dealer)

7. Bookkeeping record (recorded payment of bills for subscriptions)

8. Checking record (recorded current receipts, binding information, claims)

9. Binding dummies (filed in circulation department file to designate volumes at the bindery)

ı. Unclassified file (divided into eight sections for U.S. documents, state documents, local documents, agricultural experiment station reports, etc. Records receipts and holdings)

I I. Travel catalog (maintained by the catalog department so that a temporary card could be placed in the public cata$\log$ when a card was withdrawn to record additional holdings)

12. Continuation file (a file maintained by the purchase division to record annuals, yearbooks, etc.)

During the time that this multiplying of records was taking place, the serial collection at Ohio State continued to grow until at the time of the survey we had 18,513 classified titles of which 4,633 were being currently received. It is estimated that we receive 658 documents of a serial nature, and 725 unclassified serial titles come to us as gifts or through exchange. It is estimated 
that we will add approximately 425 new titles annually for the next few years.

It does not require a detailed study in cost accounting to show that these methods of keeping serial records, when applied to a serial collection of this size, cost the library a considerable sum of money for just routine maintenance. This waste was multiplied because of the duplication and overlapping of records, and inaccuracy in bibliographic checking was the result of no one record giving complete information regarding a serial title.

The solution, or at least the alleviation of this unhappy situation, presented itself in the form of an equipment budget which came with the new $\$ 2,500$,000 addition to the library. The new building gave the staff adequate work space in departments which, for the first time, were located to facilitate the orderly and efficient processing of material and service to the patron. The technique or medium used for the consolidation of serial records is known as the Central Serial Record.

\section{I}

Before discussing specific aspects of the Central Serial Record, there are two observations that should be made. The first is that it is impossible to plan intelligently the centralization of serial records for the purpose of increasing efficiency without balancing the administrative advantages against the possible inconveniences to the library patron. If the holding record, for example, were incorporated into a central record housed in the Serial Division, a sometimes needed record would be withdrawn from the borrower's direct use. It must be decided whether the borrower will be too seriously handicapped by not having a list of holdings available at a public service point, e.g., the public catalog. If it is decided to remove this record, then methods of efficient communication (telephone, pneumatic tube, telautograph, etc.) must be worked out to provide the necessary service required.

If the problems incident to the centralization of the serial records could be reduced to one word, that word would be communications. When any record is withdrawn from a processing or service point, the information must be available either through mechanical means or personal service. This assumes, of course, that the record is not duplicated in some other file.

The second general observation is that it is highly improbable that any one department can draft a satisfactory plan for centralizing serial records without actively consulting and compromising with the other departments in the library. The Acquisition Department, for instance, may draw up plans highly satisfactory for their purposes, but may neglect service and administrative problems concerning circulation, reference, documents, departmental libraries, bindery and cataloging. Any consolidation of records will affect an undetermined number of departments directly or indirectly, and only by consulting these departments can complications be avoided after a central serials program is in operation. It was to avoid this mistake that the Central Serial Records Committee at Ohio State represented all major departments of the libraries.

\section{II}

The first step in approaching the establishment of a Central Serial Record is to decide what it will contain. This is tantamount to determining what the function of the record shall be. The decision also implies a full recognition of financial considerations and administrative problems. From the first, it is inescapable that it costs money to shift records. Visible filing equipment to house the records is highly desirable for a Central Serial Record and it costs a considerable amount. 
In deference to cost considerations alone, a library may be forced to consolidate only the records pertaining to the currently received titles which generally constitute about one-third of the titles held. The more money a library has available for personnel and equipment, the more categories of serials may be included in a Central Serial Record, e.g., inactive serials, unclassified serials, documents of a serial nature, and serials received as a gift or on exchange.

The location of departments in the library building may prevent the inclusion of certain records.

The administrative organization and desirability for the status quo in certain departments might eliminate the possibility of including such items as serial documents, if documents were handled by a strong and well-organized division. There are many other variables which are peculiar to individual libraries. They must all be examined and measured before the scope of inclusion in a Central Serial Record can be wisely determined.

It should be noted that the creation of a comprehensive Central Serial Record logically precludes a "weak" serials division. It is obvious that if all the records are centralized, the functions incident to the maintenance of these records will tend to be centralized.

\section{III}

\section{Inclusion}

To eliminate the cost and errors resulting from having to maintain and to check a variety of files to determine serial holdings, it was decided that all serials, including documents, subscriptions, receipts from gift or exchange, current or discontinued, classified or unclassified material, and serials classified as separates, should be included in the Central Serial Record at Ohio State. The definition for "serial" was taken from the American Library Association Cataloging Rules: "A serial is a publication issued at more or less frequent intervals in numerical or chronological sequence, which is intended to be continued indefinitely." A patron or bibliographer will no longer have to search the Public Periodical Catalog for bound classified holdings, the checking file for bound and unbound classified holdings, the unclassified file for unclassified material, two different files for unclassified state and local documents, and the miscellaneous file for serials received as gifts or on exchange.

The only list of holdings is to be recorded in the Record. There will be no holdings record directly accessible to the library patron. This decision was the result of balancing the equities concerning public service and library administration. It is based on the premise that the great majority of borrowers simply want a particular issue of a serial-they are not interested in holdings per se. For the marginal few that do research which requires knowledge of our holdings, there is available for the first time a comprehensive record which may be used by arrangement with the Serial Division. For all questions concerning holdings which arise at the circulation desk, provision is made for communication to the Central Serial Record either by telephone or by pneumatic tube. Telephone communication is available for the periodical service desk on the second floor.

Of the twelve records which were formerly maintained, four were abolished so far as serials records are concerned: I) Shelf list, 2) Sheet shelf list, 3) Accession book, 4) Travel catalog. Five serial records were consolidated into the Central Serial Record: I) Public periodical catalog, 2) Bookkeeping record, 3) Checking record, 4) Unclassified file, 5) Continuation file. Three of the former serial records were maintained as they were: I ) public dictionary catalog, 2) order card record, 3) binding dummies in the circulation file. Of the three records which were retained, only the binding dummy record is active. It was retained to 
assist the circulation staff in servicing requests for serials which may be at the bindery. After a test period it may be found that service questions involving this problem will be sufficiently negligible and will allow us to discontinue the binding dummy record and rely on mechanical communications with the Central Serial Record.

\section{Equipment}

As the serial checking record has been maintained on regular size catalog cards in conventional catalog trays, the Serial Division has never been able to solve satisfactorily the problem of checking for missing numbers and claiming them. It was evident that a progressive signal system was needed that would give notice when issues of a title had not been received and would also indicate claims which had been made but not answered. The use of metal signal clips was considered too clumsy, bulky, and time-consuming.

Studies have indicated that "visible" filing equipment, which makes each entry immediately visible, is an important saver when the records are constantly used for checking receipts and for general bibliographic reference. This consideration directed the Committee to make a thorough study of the various types and makes of visible filing equipment. It should be noted that decisions regarding equipment should be based on the type of record that an institution is creating. The most suitable type of equipment depends on the anticipated function of the record.

Before deciding on the type of equipment that would be desirable. it is necessary to examine how the files will be used and by whom. The number of titles to be recorded also plays an important part in this decision. In a library with approximately 5,00o currently received titles, it is probable that the person checking serials and recording their receipt will be using the file more con- stantly than those seeking bibliographic information. This dictates that the files concerning the checking clerk must be easily accessible for posting from rather bulky media-the serials themselves. Obtaining bibliographic information and reporting holdings constitute the second largest demand that would be made on the file. This means that the record must be accessible to a number of different people at the same time, and, so far as possible, they should not interrupt each other in their use of the file.

As a Central Serial Record is a permanent record, an over-all consideration is the problem of card depreciation. Through the years a serial record becomes a rather complex affair. For this reason, the filing equipment must provide adequate protection for the record so that the library will not be faced with the possibility of having to transpose records from cards which tear or wear out through constant use.

After examining several types of equipment, the Committee and the Directors' Office decided on the Acme visible file. It seemed to offer advantages not found in competing equipment. The Acme cards are suspended by metal hangers from wires which are mounted in the tray. This means that both sides of the card can be used. In other types of equipment the cards are mounted on flaps or pockets which preclude the use of both sides of the card. With the wire hanger arrangement, it is possible to suspend two cards from the same wire. If one card becomes filled, but it is desirable to retain it in the file, a second card can be hung along with it. It is also possible to place a "rider" over the card for temporary notes. This consists of regular bond paper which is cut the same size as the card except for a flap which folds over the top of the card to keep it in place.

The Acme cards can be punched so that a celluloid footing can be attached which 
will protect the exposed portion of the card when it is in the file. The footing provides for the use of the sliding bar signal tab which can be calibrated and used to show the progressive receipt of a title. If a title is in arrears the tab will not be forwarded to the next position. As a result, it will be easy to spot when the files are examined for claims.

At this juncture the question of the type or size of cabinet must be examined. Remembering that the Record would be most actively used for checking in material, it was necessary to restrict the cabinet to a size that would be convenient for the constant posting of some 5,000 active titles. It was also necessary to house approximately I 5,000 titles, which, for one reason or another, have been discontinued.

There seemed to be three alternatives:

I. Purchase several of the largest cabinets, each with a capacity of 12,690 cards. These cabinets could provide compact housing, but they would have the attending disadvantage to the checking clerk of having to reach below her posting table for the bottom trays and having to stand up to reach the top ones. Compactness also meant that the number of people using the file at one time would be limited.

2. Purchase enough cabinets of "posting height" to contain the record and string them around the room. This would take 20 feet of space, cost more than two large units, and make the record more difficult to work with because of the space problem.

3. Purchase a combination of "posting height" ( 6 inches high) cabinets for the checking record and two of the large units for the permanent record.

The third alternative seemed to kill quite a few birds with one combination. It is largely supported by deciding that an effective Central Serial Record should have checking cards as well as permanent cards. It was felt that it would not be satisfactory to compose the permanent record of serial holdings by just interfiling completed checking cards. The third method allows for greater flexibility and more efficiency. The checking clerk would seldom be interrupted at her work. Permanent holdings would be sufficiently compact so that a bibliographer or research worker could easily reach the title in which he or she was interested. The most active use, i.e., checking, would be restricted to files containing temporary checking cards and would not cause depreciation of the permanent cards.

Quite early in the study the Committee realized that the library patron who knew the serial title he wanted, but needed the call number, would be at a disadvantage in having to use the public dictionary catalog to ascertain the call number and location. The public periodical catalog would no longer be there to serve such a purpose. It was decided that an even more satisfactory method of listing call numbers could be provided by means of Flexoline files, which are vertically hinged panels into which strips of cardboard can be interfiled. Flexoline files, each with a capacity of 7000 titles, will be located in the periodical service area on the second floor and in the Public Catalog area on the first floor. Each entry will give call number and title. Location will be indicated if the serial is shelved in a location other than the Main Library. Different colored strips will be used to indicate documents, cross reference, and serials received on subscription. Only classified serials enjoying the most general use will be entered in the Flexoline file. Call numbers for the balance of the serial titles which are only occasionally requested will have to be found in the Public Dictionary Catalog.

\section{Cards}

Designing the cards for a Central Serial Record can present some of the most challenging problems in the entire planning operation. Once the design is "frozen" 
and the cards printed, it is necessary to live with them until the supply is exhausted unless the library is willing to throw several hundred dollars' worth of stock in the waste basket and start over. For this reason the
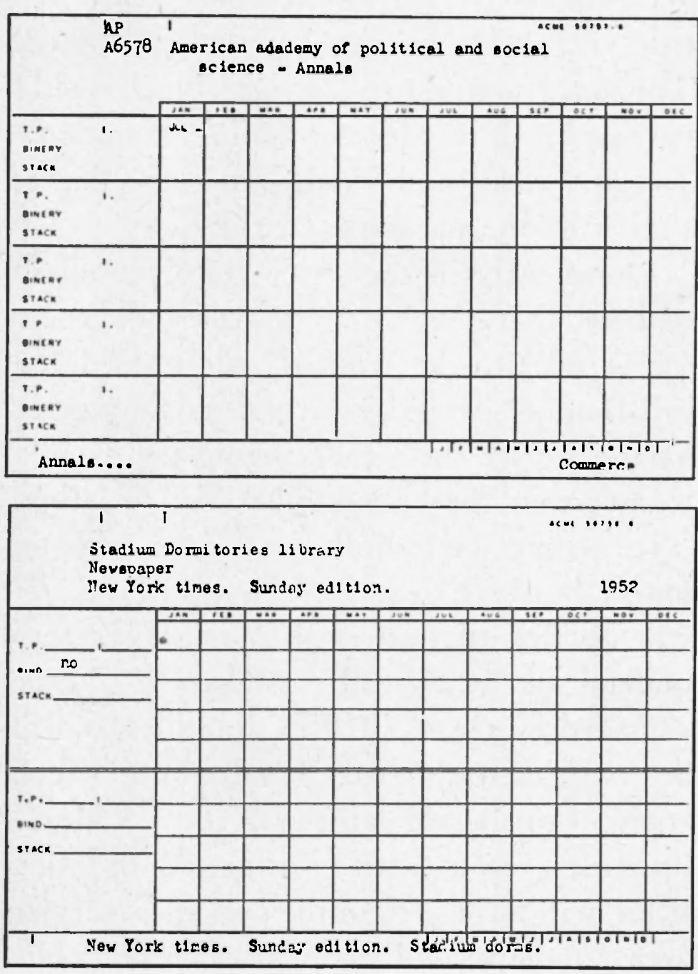

Checking Card

Committee made a thorough study of cards used by other institutions before proceeding to draft cards for our own purposes.

The original decision as to which records to incorporate into the Central Serial Record determined the function that the cards should perform.

The real problem is to transpose these functions into terms of space which is limited by the size of the card. It was decided that a $4 \times 6$ inch card would be adequate for our purposes.

The cards in the permanent file contain the same information on the front as those for the checking file, except that no ruled spaces are provided for recording holdings. The space is left blank. Nothing is printed on the back of the card. The general design of all cards was kept as uniform as possible, as visible alignment is a factor to be considered in designing cards for efficient use.

It was necessary to design eight types of cards to meet the requirements of both the checking and permanent files.

Cards for checking file:
I. Daily
2. Weekly
3. Monthly
4. Annual
5. Numerical
6. Cross reference (blank cards)
7. Irregular

Cards for permanent file:

I. Permanent card

2. Cross reference-same as in the checking file

The irregular card was designed to record call numbers for monographic serials which are classified as separates.

Four pastel colors of card stock were selected to stand for serials received through: I) Subscription, 2) Gift or exchange, 3) Document deposit and document subscription, and 4) Cross references. The use of different colors will be a visual aid for the Gift \& Exchange librarian and the Documents librarian in allowing them to find or survey their titles more easily.

\section{Processing}

The Purchase Division of the Acquisition Department orders all serials which are to be placed on subscription. At the time that the order is sent, the checking card and work slip are typed. The checking card goes to the Serial Division where it is filed in the Central Serial Record. The work slip, which is printed on a bond paper "rider" is placed over the card. When the first issue of the serial is received it is checked in and sent, along with the work slip, to the serials cataloger. The serials cataloger decides whether the entry as estab- 
lished is correct, whether the serial shall be analyzed, and whether it shall be classified. If it is to be classified, the call number is entered on the work slip. The work slip, with notes referring to the decisions mentioned above, is then returned to the Central Serial Record where the information is transcribed to the checking card. Flexoline strips are then typed for each of the two Flexoline files and are forwarded to the Reference librarian and the Periodical Service librarian. They may, or may not, interfile the new title in their Flexoline files, depending upon their estimate as to how much demand will be made for that particular title. It should be remembered that these files are selective and are designed primarily as a location guide and an easy method for locating call numbers.

\section{Summary}

Centralizing serial records is nothing new to serials librarianship, but the concept of a Central Serial Record seems to be a product of the past decade. It is a development which has been largely forced on larger libraries by the growing complexity and increased administrative costs connected with maintaining records for their serial holdings. It has been made possible by critically examining the actual use made of records which have been kept for the sake of the custom. Duplicate records, and records whose use did not warrant their maintenance, have been eliminated. Records which were found to be necessary to the efficient management of the Serials Division have been consolidated into filing equipment that performs far greater service than the conventional catalog tray. Mechanical methods of communication have come to play an increasingly important part, as it has been realized that the installation of a telephone or the extension of a pneumatic tube system would be quickly paid for by the savings resulting from record consolidation. Despite some slight delay for the marginal patron who has to know the holdings of a particular title, it is felt that patron service on the research level has taken a great step forward by the provision of a comprehensive serial record.

\section{Defrosting a Frozen Asset}

\section{(Continued from page 38)}

access to dissertation materials will become immensely easier than before and the heavy burden of interlibrary loan will be correspondingly eased by the elimination of dissertations from the loan code. The machinery of interlibrary loan is already creaky and showing signs of distress and any relief will be most welcome. It may mean moreover that the costly binding of dissertations may in the future be eliminated.

To the extent that degree granting in- stitutions cooperate and participate in the plan, it will succeed. It should be a prime obligation of every librarian interested in the future of advanced scholarship to bring the plan before the Graduate School at as early a date as possible and to support it vigorously. Organized regular listing of dissertations coupled with availability of abstracts and facilities for gaining prompt access to the complete texts will defrost this frozen asset of American scholarship. 